\title{
A Cross-sectional Study to Evaluate the Periodontal Health Status of Construction Workers with and without Tobacco Habits in New Delhi, India
}

\author{
${ }^{1}$ Nilima Sharma, ${ }^{2}$ Sukhvinder S Oberoi
}

\begin{abstract}
Background: Major constituent of the lower socioeconomic group is comprised of the construction working population. The neglected oral hygiene is evident by the ill oral and its systemic effects often observed in these strata of society. Thus the present study was planned and executed to evaluate the periodontal status in the low socioeconomic strata.
\end{abstract}

Materials and methods: A total of 154 subjects aged between 15 years and 60 years were examined. The community periodontal index for treatment needs (CPITN) using the CPITN probe and a mouth mirror was used to record the periodontal status. The post-hoc analysis for inter-group comparison of the $\mathrm{CPI}$ and loss of attachment (LOA) scores among different age groups was done using the Tukey post-hoc test.

Results: Different age group showed a significant difference in $\mathrm{CPI}$ and LOA scores. The mean LOA score 0 was found to be significantly ( $p$ value $<0.05$ ) more among Never smokers whereas the mean LOA score 1 was found to be significantly ( $p$ value $<0.05$ ) more among present smokers.

Conclusion: Non-users, smoked tobacco users, smokeless tobacco users, and both smoked and smokeless tobacco users showed a significant difference ( $p$ value $<0.05$ ) in the mean CPI score and LOA scores ( $p$ value $<0.05$ ).

Keywords: Community periodontal index for treatment needs, Periodontal disease, Smokeless tobacco, Smoking.

How to cite this article: Sharma N, Oberoi SS. A Crosssectional Study to Evaluate the Periodontal Health Status of Construction Workers with and without Tobacco Habits in New Delhi, India. J Contemp Dent 2018;8(3):120-124.

Source of support: Nil

Conflict of interest: None

\section{INTRODUCTION}

Periodontal diseases constitute the majority of the dental problems; this affects people worldwide and the inhabitants of the Indian subcontinent are no exception to it. Different age groups show the varied extent and

${ }^{1}$ Associate Professor, ${ }^{2}$ Reader

${ }^{1}$ Department of Dentistry, Hamdard Institute of Medical Sciences and Research and HAH Centenary Hospital, New Delhi, India

2Department of Public Health Dentistry, Genesis Dental College, Ferozpur, Punjab, India

Corresponding Author: Nilima Sharma, Associate Professor, Department of Dentistry, Hamdard Institute of Medical Sciences and Research and HAH Centenary Hospital, New Delhi, India, e-mail: nilimasharma@yahoo.com the severity of periodontal disease. ${ }^{1}$ Various risk factors such as environmental, biologic, occupational play an important role in its etiopathogenesis.

The lower socioeconomic group in India is comprised in the majority by the building construction workers. Smoking, chewing tobacco and drinking habits are common amongst this strata, this predisposes to adverse oral health, particularly those pertaining to the oral mucosa. $^{2}$

The longitudinal effects of smoking on periodontal health has been investigated by a few prospective studies. ${ }^{3-5}$ Literature reports the rate of bone loss among smokers to be greater than that of non-smokers( almost four times). ${ }^{3}$ Prevalence and severity of furcation attachment loss observed in smokers are also high. ${ }^{6}$ Greater tooth loss is also observed in smokers as compared to nonsmokers. ${ }^{7,8}$ Patients referred to a periodontist were either current or past smokers (75\%), when compared to $54 \%$ of patients in general practices. ${ }^{9}$

Smokers also exhibit sites colonized with a larger proportion of Periodontal pathogens. Smoking is a risk factor with odds ratios for periodontitis in the range of $2-7 .^{10}$ Diminished numbers of helper lymphocytes in smokers is reported in studies, which consequently affects both B cell function and antibody production. ${ }^{11,12}$

Thus this cross-sectional study was planned and executed to assess the effect of the smokeless and smoked tobacco on periodontal status in the low socioeconomic strata.

\section{MATERIALS AND METHODS}

\section{Study Area and Design}

A cross-sectional descriptive survey was conducted to assess the periodontal status among 15 years and 60 years old construction workers with and without tobacco habits in the Jamia Hamdard campus, New Delhi, India. Both male and female construction workers aged between 15 years and 60 years using tobacco constituted the study group.

\section{Ethical Clearance and Informed Consent}

The Institutional Review Board of Jamia Hamdard reviewed the study protocol, and ethical clearance was 
given by the Institutional Ethics Committee. Written informed consents approved by the JHIEC were obtained from all the participants who had a habit of tobacco use (either smoking, use of smokeless tobacco or both) or no tobacco usage constitutes the study subjects. Those subjects under the age of 18 the written informed consent approved by the JHIEC was sought by the parents/ guardians.

\section{Study Proforma}

The survey proforma was in accordance with the World Health Organization (WHO) oral health assessment form. ${ }^{13}$ The general information included the demographic data (age, gender, the level of education, oral hygiene practices and adverse oral habits.) and the periodontal health status was measured using the community periodontal index and $\mathrm{LOA}^{13}$

\section{Sampling Design}

The study sample was collected using the convenient sampling method. The construction sites were selected which were near to the Jamia Hamdard Hospital. The building construction workers who fulfilled the inclusion and exclusion criteria were selected.

\section{Inclusion Criteria}

- Construction workers aged 15 years and above.

- Construction workers working at different construction sites in Jamia Hamdard campus and willing to participate in the study.

\section{Exclusion Criteria}

- Construction workers with any systemic disease that adversely affect oral health.

- Construction workers who were not willing for the clinical oral examination.

\section{Data Collection}

A total of 154 subjects aged between 15 years and 60 years were examined. The CPI $(1982)^{13}$ was used to record the periodontal status by using the CPITN probe and a mouth mirror. Gingival bleeding, calculus, and periodontal pockets were used for assessment of periodontal tissues. The study population was divided into different age groups as per the WHO index age group criteria. The socioeconomic status was determined by the Kuppuswamy scale. ${ }^{14}$

The periodontal examination was carried out by a qualified periodontist using a plain mouth mirror and a WHO 621 periodontal probe. LOA was recorded from index teeth to obtain an estimate of the lifetime accumulated destruction of the periodontal attachment.

\section{Statistical Analysis}

The statistical analysis was performed using the statistical package for social sciences (SPSS) version 21.0. The comparison of mean CPI scores was done among the various age groups using the one-way analysis of variance (ANOVA) test. The post-hoc analysis for inter-group comparison of the CPI scores among different age groups was done using the Tukey post-hoc test.

\section{RESULTS}

Among construction workers, there were 77 (55.0\%) subjects from 15 to 25 years age group, 38 (24.7\%) subjects from 26 to 35 years age group, 29 (18.8\%) subjects from $36-50$ years age group and $10(6.5 \%)$ subjects from above 50 years age group.

One-way ANOVA test was used for comparison of mean CPI score 0 , CPI score 1, CPI score 2, CPI score 3, CPI score 4 and $\mathrm{CPI}$ score $\mathrm{X}$ was done among the various age groups. There was a significant difference in CPI score 0 , $1,2,3,4$ and $X$ score between different age groups. The inter-group comparison between the different age groups showed that the mean CPI score 1 (bleeding observed directly or by using a mouth mirror after probing) was significantly more among 36 to 50 years age group in comparison to $15-25$ years age group. The mean CPI score 2 (Calculus detected during probing but all of the black band on the probe visible) was significantly more among $15-25$ years, $26-35$ years and $36-50$ years in comparison to more than 50 years age group. The mean CPI score 3 (Pocket $4-5 \mathrm{~mm}$ ) was significantly more among those above 50 years age group in comparison to 15-25 years and 26-35 years. The mean CPI score 4 (Pocket 6 $\mathrm{mm}$ or more) was significantly more among more than $36-50$ years age group in comparison to $15-25$ years and 26-35 years. The mean CPI score $X$ (Excluded sextant) was significantly more among the greater than 50 years age group in comparison to $15-25$ years, $26-35$ years and 36-50 years (Table 1 ).

The comparison of mean LOA score 0, LOA score 1, LOA score 2, LOA score 3 , LOA score 4 and LOA score $X$ was done among $15-25$ years, $26-35$ years, $36-50$ years and More than 50 years age group using the one-way ANOVA test which showed a significant difference across the age groups. The post-hoc analysis for intergroup comparison of the LOA scores among different age groups was done using the Tukey post-hoc test. The LOA score 0 was significantly more among $15-25$ years and 26-35 years in comparison to 36-50 years and More than 50 years. The LOA scores 1, 2, 3 and 4 showed a significant increase with age with higher scores reported among 36 to 50 and more than 50 years age groups (Table 2). 


\begin{tabular}{|c|c|c|c|c|c|c|c|c|}
\hline & & $\begin{array}{l}15-25 \\
\text { years (1) }\end{array}$ & $\begin{array}{l}26-35 \\
\text { years (2) }\end{array}$ & $\begin{array}{l}36-50 \\
\text { years (3) }\end{array}$ & $\begin{array}{l}\text { More than } 50 \\
\text { years (4) }\end{array}$ & Over-all & $p$ value ${ }^{a}$ & $\begin{array}{l}\text { Post-hoc } \\
\text { comparisons }^{b}\end{array}$ \\
\hline \multirow[t]{2}{*}{ CPI score 0} & Mean & 0.30 & 0.29 & 0.07 & 0.10 & 0.19 & $0.001^{*}$ & $1,2>3,4$ \\
\hline & SD & 0.08 & 0.06 & 0.03 & 0.05 & 0.06 & & \\
\hline \multirow[t]{2}{*}{ CPI score 1} & Mean & 0.71 & 0.39 & 0.17 & 0.20 & 0.37 & $0.011^{*}$ & $1>2>3,4$ \\
\hline & SD & 0.13 & 0.12 & 0.05 & 0.06 & 0.09 & & \\
\hline \multirow[t]{2}{*}{ CPI score 2} & Mean & 4.70 & 4.84 & 4.69 & 3.50 & 4.43 & $0.008^{*}$ & $1,2,3>4$ \\
\hline & SD & 1.25 & 1.30 & 1.37 & 1.10 & 1.26 & & \\
\hline \multirow[t]{2}{*}{ CPI score 3} & Mean & 0.23 & 0.47 & 0.69 & 1.50 & 0.72 & $<0.001^{*}$ & $4>3>1,2$ \\
\hline & SD & 0.04 & 0.18 & 0.21 & 0.37 & 0.20 & & \\
\hline \multirow[t]{2}{*}{ CPI score 4} & Mean & 0.04 & 0.00 & 0.31 & 0.48 & 0.21 & $0.025^{*}$ & $4>3>1,2$ \\
\hline & SD & 0.01 & 0.00 & 0.10 & 0.03 & 0.04 & & \\
\hline \multirow[t]{2}{*}{ CPI score $X$} & Mean & 0.00 & 0.00 & 0.07 & 0.80 & 0.22 & $<0.001^{*}$ & $4>3>1,2$ \\
\hline & SD & 0.00 & 0.00 & 0.02 & 0.27 & 0.07 & & \\
\hline \multicolumn{9}{|c|}{${ }^{\mathrm{a} O n e-w a y ~ A N O V A ~ t e s t ; ~}{ }^{\mathrm{b}}$ Post-hoc tukey test; *Significant difference } \\
\hline \multicolumn{9}{|c|}{ Table 2: Comparison of Mean LOA scores between different age groups } \\
\hline & & $\begin{array}{l}15-25 \\
\text { years (1) }\end{array}$ & $\begin{array}{l}26-35 \\
\text { years (2) }\end{array}$ & $\begin{array}{l}36-50 \\
\text { years (3) }\end{array}$ & $\begin{array}{l}\text { More than } 50 \\
\text { years (4) }\end{array}$ & Over-all & $p$ value ${ }^{a}$ & $\begin{array}{l}\text { Post-hoc } \\
\text { comparisons }^{b}\end{array}$ \\
\hline \multirow[t]{2}{*}{ LOA score 0} & Mean & 5.60 & 5.08 & 3.21 & 2.60 & 4.12 & $0.001^{*}$ & $1,2>3>4$ \\
\hline & SD & 1.78 & 1.55 & 1.01 & 0.98 & 1.33 & & \\
\hline \multirow[t]{2}{*}{ LOA score 1} & Mean & 0.27 & 0.66 & 1.83 & 1.70 & 1.12 & $0.005^{*}$ & $3,4>2>1$ \\
\hline & SD & 0.09 & 0.18 & 0.66 & 0.70 & 0.41 & & \\
\hline \multirow[t]{2}{*}{ LOA score 2} & Mean & 0.10 & 0.18 & 0.70 & 0.80 & 0.45 & $0.019^{*}$ & $3,4>1,2$ \\
\hline & SD & 0.02 & 0.04 & 0.16 & 0.18 & 0.10 & & \\
\hline \multirow[t]{2}{*}{ LOA score 3} & Mean & 0.01 & 0.05 & 0.08 & 0.10 & 0.06 & $0.031^{*}$ & $3,4>2>1$ \\
\hline & SD & 0.01 & 0.02 & 0.03 & 0.03 & 0.02 & & \\
\hline \multirow[t]{2}{*}{ LOA score 4} & Mean & 0.00 & 0.03 & 0.25 & 0.31 & 0.15 & $0.035^{*}$ & $4>3>1,2$ \\
\hline & SD & 0.00 & 0.01 & 0.09 & 0.10 & 0.05 & & \\
\hline \multirow[t]{2}{*}{ LOA score $X$} & Mean & 0.01 & 0.00 & 0.27 & 0.50 & 0.20 & $<0.001^{*}$ & $4>3>1,2$ \\
\hline & SD & 0.01 & 0.00 & 0.09 & 0.18 & 0.07 & & \\
\hline
\end{tabular}

aOne-way ANOVA test; ${ }^{\text {b} P o s t-h o c ~ t u k e y ~ t e s t ; ~ * S i g n i f i c a n t ~ d i f f e r e n c e ~}$

There was a significant difference (p-value $<0.05)$ in the mean CPI score between non-users, smoked tobacco users, smokeless tobacco users and Both smoked and smokeless tobacco users. The mean CPI score was significantly more among tobacco users in comparison to the non-users. The mean CPI score 0 and 1 was significantly more among non-users whereas CPI score 2 was significantly more among smoked tobacco users, Smokeless tobacco users and both smoked and smokeless tobacco users. The mean CPI score 3 and 4 was significantly more among smokeless tobacco users and both smoked and smokeless tobacco users in comparison to smoked tobacco users alone which was significantly more than non-users (Table 3).

Non-users, smoked tobacco users, smokeless tobacco users, and both smoked and smokeless tobacco users showed a significant difference ( $p$ value $<0.05$ ) in the mean LOA score. The mean LOA score 1 and 2 was significantly more among smoked tobacco users and both smoked and smokeless tobacco users. The mean LOA score 3 and 4 was significantly more among smoked tobacco users, smokeless tobacco users and both smoked and smokeless tobacco users (Table 4).

\section{DISCUSSION}

Gingivitis was significantly predominant among 36-50 years age group and a higher incidence of periodontitis was observed in 36-50 years age group and above 50 years. Those above the 50 years age group presented with the highest score of $X$ (excluded sextant). LOA scores, when compared within various age groups, showed a greater score in the higher age groups.

Waerhaug et al. explain the strong correlation between age, and periodontal breakdown is attributed to the altered equilibrium between plaque attack and host response. ${ }^{15}$ Literature reports the prevalence of periodontal disease of any degree to be $98.3 \%{ }^{16}$ Also, data from German factory workers ${ }_{1}^{17}$ marble mine ${ }^{18}$ and beedi factory workers ${ }^{19}$ revealed none of the workers were free of periodontal disease.

The CPI gives normative rather than scientific information. It gives no information about the natural history of periodontal disease and is not a specific detector of the destructive agents in periodontal disease. Assessment of treatment needs was excluded as it has become complicated due to recent advances in the understanding the etiology, pathogenesis, and treatment of the disease. ${ }^{20}$ 
A Cross-sectional Study to Evaluate the Periodontal Health Status of Construction Workers with and without Tobacco Habits

Table 3: Comparison of mean CPI scores among tobacco users and non-users

\begin{tabular}{|c|c|c|c|c|c|c|c|c|c|c|c|c|}
\hline & \multicolumn{2}{|c|}{ CPI score 0} & \multicolumn{2}{|c|}{ CPI score 1} & \multicolumn{2}{|c|}{ CPI score 2} & \multicolumn{2}{|c|}{ CPI score 3} & \multicolumn{2}{|c|}{ CPI score 4} & \multicolumn{2}{|c|}{ CPI score $X$} \\
\hline & Mean & $S D$ & Mean & $S D$ & Mean & $S D$ & Mean & $S D$ & Mean & $S D$ & Mean & $S D$ \\
\hline Non-user ${ }^{(1)}$ & 0.42 & 0.13 & 0.47 & 0.16 & 4.00 & 1.23 & 0.23 & 0.10 & 0.02 & 0.01 & 0.00 & 0.00 \\
\hline Smoked tobacco users ${ }^{(2)}$ & 0.19 & 0.06 & 0.40 & 0.12 & 4.42 & 1.10 & 0.70 & 0.21 & 0.14 & 0.04 & 0.14 & 0.04 \\
\hline Smokeless tobacco users ${ }^{(3)}$ & 0.21 & 0.11 & 0.50 & 0.18 & 4.81 & 1.32 & 0.40 & 0.13 & 0.09 & 0.03 & 0.00 & 0.00 \\
\hline $\begin{array}{l}\text { Both smoked and smokeless } \\
\text { tobacco users }{ }^{(4)}\end{array}$ & 0.43 & 0.14 & 1.29 & 0.38 & 4.64 & 1.12 & 0.39 & 0.11 & 0.10 & 0.04 & 0.00 & 0.00 \\
\hline Over-all & 0.31 & 0.11 & 0.67 & 0.21 & 4.47 & 1.19 & 0.43 & 0.14 & 0.09 & 0.03 & 0.04 & 0.01 \\
\hline$p$ value & \multicolumn{2}{|c|}{$0.023^{*}$} & \multicolumn{2}{|c|}{$<0.001^{*}$} & \multicolumn{2}{|c|}{$0.049^{*}$} & \multicolumn{2}{|c|}{$0.044^{*}$} & \multicolumn{2}{|c|}{$0.039^{*}$} & \multicolumn{2}{|l|}{$0.048^{*}$} \\
\hline post-hoc comparisons & \multicolumn{2}{|c|}{$1,4>2,3$} & \multicolumn{2}{|c|}{$4>1,2,3$} & \multicolumn{2}{|c|}{$2,3,4>1$} & \multicolumn{2}{|c|}{$2>3,4>1$} & \multicolumn{2}{|c|}{$2>3,4>1$} & \multicolumn{2}{|c|}{$2>1,3,4$} \\
\hline
\end{tabular}

aOne-way ANOVA test; ${ }^{\mathrm{b}}$ Post-hoc tukey test; *Significant difference

Table 4: Comparison of mean LOA scores among tobacco users and non-users

\begin{tabular}{|c|c|c|c|c|c|c|c|c|c|c|c|c|}
\hline & \multicolumn{2}{|c|}{ LOA score 0} & \multicolumn{2}{|c|}{ LOA score 1} & \multicolumn{2}{|c|}{ LOA score 2} & \multicolumn{2}{|c|}{ LOA score 3} & \multicolumn{2}{|c|}{ LOA score 4} & \multicolumn{2}{|c|}{ LOA score $X$} \\
\hline & Mean & $S D$ & Mean & $S D$ & Mean & $S D$ & Mean & $S D$ & Mean & $S D$ & Mean & $S D$ \\
\hline Non-user ${ }^{(1)}$ & 5.17 & 2.09 & 0.53 & 0.15 & 0.17 & 0.04 & 0.00 & 0.00 & 0.00 & 0.00 & 0.00 & 0.00 \\
\hline Smoked tobacco users ${ }^{(2)}$ & 4.07 & 1.33 & 1.14 & 0.34 & 0.53 & 0.11 & 0.05 & 0.02 & 0.04 & 0.02 & 0.14 & 0.04 \\
\hline Smokeless tobacco users $^{(3)}$ & 5.12 & 2.12 & 0.89 & 0.18 & 0.24 & 0.09 & 0.04 & 0.01 & 0.02 & 0.01 & 0.00 & 0.00 \\
\hline $\begin{array}{l}\text { Both smoked and smokeless } \\
\text { tobacco users }{ }^{(4)}\end{array}$ & 4.86 & 2.01 & 1.14 & 0.32 & 0.40 & 0.13 & 0.04 & 0.02 & 0.02 & 0.01 & 0.00 & 0.00 \\
\hline Over-all & 4.81 & 1.89 & 0.93 & 0.25 & 0.34 & 0.09 & 0.03 & 0.01 & 0.00 & 0.00 & 0.04 & 0.01 \\
\hline$p$ value & 0.098 & & $0.020^{*}$ & & $0.012^{*}$ & & $0.021^{*}$ & & $0.046^{*}$ & & $0.048^{*}$ & \\
\hline post-hoc comparisons & $\mathrm{N} / \mathrm{A}$ & & $2,4>3$ & $>1$ & $2,4>3$ & & $2,3,4>1$ & & $2>3,4$ & & $2>1,3$, & \\
\hline
\end{tabular}

ane-way ANOVA test; ${ }^{\text {b} P o s t-h o c ~ t u k e y ~ t e s t ; ~ * S i g n i f i c a n t ~ d i f f e r e n c e ~}$

Understandably, the mean LOA score 0 was found to be significantly ( $\mathrm{p}$ value $<0.05$ ) more among never smokers whereas the mean LOA score 1 was found to be significantly ( $p$ value $<0.05$ ) more among present smokers. A 6-year longitudinal study in the literature reported smokers had $50 \%$ less improvement in probing depth and CAL than non-smokers. ${ }^{21}$

A clinical study of patients treated in general dental practice reported that the percentage of sites with probing depths greater than $4 \mathrm{~mm}$ was $15 \%$ in young smokers as compared to $6 \%$ in non-smokers. ${ }^{22}$

A significant difference in the CPI scores $0,1,2,3,4$, and $X$ between non-tobacco users and smoked, smokeless and both smoked and smokeless tobacco users was observed. This is in conjunction with reports from literature; in examination confined to facial surfaces of mandibular incisor teeth (where quid of smokeless tobacco is commonly kept), significant increases in both gingival recession and attachment loss. ${ }^{23}$

Tobacco is consumed in both smoking and smokeless forms. Beedi ( made with tobacco wrapped in a Bauhinia Racemosa leaf is a form of cigarette) is a popular form of tobacco smoked in several countries in South East Asia and the Middle East. Higher incidence of severe periodontitis is found in cigarette smokers than snuff users. ${ }^{21}$

Compared with never-smokers, long-term smokers had very high odds ratios (ORs of 7.1 and 5.7 respectively) for having $1+$ sites with $5+\mathrm{mm}$ attachment loss. ${ }^{24}$

The quality of species rather than quantity is attributed to the difference in periodontal status observed in smokers as compared to nonsmokers. ${ }^{25}$ Synergism of local effects from cigarette smoking on the pathogens environment and a deleterious effect on the host response are important factors greater severity of periodontal destruction in smokers. ${ }^{26}$

As a sequele to the apoptotic modifications induced in polymorphonuclear cells by nicotine; the lifespan of neutrophils is reduced and modulation of their bactericidal activities. ${ }^{26}$ Nicotine exposure inhibits production of superoxide anion and hydrogen peroxide which play a pivotal role in the antimicrobial action. ${ }^{27}$

The genetic and phenotypic modifications by various risk factors influence the distribution and severity of periodontal disease. With the identification of various risk factors; periodontal disease may not present a linear progression and is not age-dependent.

The regulatory ban on tobacco use by the government, the print and visual media emphasizing the deleterious effects of tobacco use; tobacco still finds its place amidst the society. The pictorial warnings on the tobacco products are not a deterrent to the habituated. Tobacco is an identifiable risk factor in the progression of periodontal disease. $^{28}$

Poor oral hygiene is an undisputed risk factor for periodontal disease; various other attributes like genetic predisposition, smoking habits, etc. play a role in its etiopathogenesis. Tobacco is an identifiable risk factor in the progression of periodontal disease. Role of genetic predisposition remains undisputed. 
In our current study, more than half of the total number of patients consumed tobacco in either smokeless or smoking form. The majority of the tobacco users justified their dependency on tobacco use as it enables them to deal with problems such as constipation, toothache and also kept them alert during their strenuous and dangerous working conditions.

Public outreach programs clarifying the myths regarding tobacco usage and highlighting the deleterious effects of tobacco should be conducted on a large scale. The crusade for a tobacco-free society should be heralded with commitment, and its recognition as a menace to the society should reach every strata of the society and all the age groups.

\section{REFERENCES}

1. Agarwal V, Khatri M, Singh G, Gupta G, Marya CM, Kumar V. Prevalence of periodontal diseases in India. J Oral Health Comm Dent 2010;4:7-16.

2. Yoshida Y, Ogawa Y, Imaki M, Nakamura T, Tanada S. Lifestyles and Periodontal Disease of Japanese Factory Workers. Environ Health Prev Med 1997;1:188-192.

3. Johnson GK, Slach NA. Impact of tobacco use on periodontal status Journal of Dental Education April 2001;65(4):313-321.

4. Machtei EE, Dunford R, Hausmann E, Grossi SG, Powell J, Cummins D, et al. Longitudinal study of prognostic factors in established periodontitis patients. J Clin Periodontol 1997; 24:102-109.

5. Beck JD, Sharp T, Koch GG, Offenbacher S. A 5-year study of attachment loss and tooth loss in community-dwelling older adults. J Periodontal Res 1997;32:516-523.

6. Kerdvongbundit V, Wikesjo UM. Effect of smoking on periodontal health in molar teeth. J Periodontol 2000;71:433-437.

7. Axelsson $\mathrm{P}$, Paulander J, Lindhe J. Relationship between smoking and dental status in 35-, 50-, 65-, and 75- year- old individuals. J Clin Periodontol 1998;25:297-305.

8. Holm G. Smoking as an additional risk for tooth loss. J Periodontol 1994;65:996-1001.

9. Haber J, Kent RL. Cigarette smoking in a periodontal practice. J Periodontol 1992;63:100-106.

10. Pihlstrom BL. Periodontal risk assessment, diagnosis and treatment planning. Periodontol 2000 2001;25:37-58.

11. Costabel U, Bross KJ, Reuter C, Ruhle KH, Matthys H. Alterations in T-cell subsets in cigarette smokers. A phenotypic analysis of bronchoalveolar and blood lymphocytes. Chest 1986;90:39-44.

12. Camelo-Castillo AJ, Mira A, Pico A, Nibali L, Henderson B, Donos N, Tomás I. Subgingival microbiota in health compared to periodontitis and the influence of smoking. Frontiers in microbiology. 2015;6:119.
13. World Health Organization, Oral health surveys. Basic methods 4th ed, Geneva: WHO, 1997.

14. Oberoi SS.. Updating Income Ranges for Kuppuswamy's Socio-Economic Status Sclae for th Year 2014. Indian Journal of Public Health, 2015;59:156-157.

15. Agarwal V, Khatri M, Singh G, Gupta G, Marya CM, Kumar V. Prevalence of periodontal diseases in India. J Oral Health Community Dent 2010;4:7-16

16. Nagarajappa R, Sanadhya S, Sharda AJ, Asawa K, Tak M, Batra M, Daryani H, Ramesh G. Assessment of the Periodontal Status among Kota Stone Workers in Jhalawar, India Clin Diagn Res. 2013 Jul;7:1498-1503.

17. Hohlfeld M, Bernimoiilin JP. Application of the community periodontal index of treatment needs (CPITN) in a group of 45-54-year-old German factory workers. J Clin Periodontol 1993;20:551-555.

18. Kumar S, Dagli RJ, Chandrakant D, Prabhu D, Suhas K. Periodontal Status of Green Marble Mine Labourers in Kesariyaji, Rajasthan, India. Oral Health Prev Dent 2008;6:217-221.

19. Shaikh H, Shankar S, Vinay S. Assessment of periodontal status and treatment needs among Beedi factory workers Harapanahalli town, Davangere district, Karnataka. JIADS 2011;2:13-17.

20. Ainamo J, Barmes D, Beagrie G, Cutress T, Martin J, SardoInfirri J. Development of the world health organization (WHO) community periodontal index of treatment needs (CPITN). Int Dent J 1982;32;281-291.

21. Kulkarni V, Uttamani JR, Bhatavadekar NB. Comparison of clinical periodontal status among habitual smokeless tobacco users and cigarette smokers. International dental journal. 2016 Feb 1;66(1):29-35.

22. Linden GJ, Mullally BH. Cigarette smoking and periodontal destruction in young adults. J Periodontol 1994;65:718-723.

23. Ernster VL, Grady DG, Greene JC, Walsh M, Robertson P, Daniels TE, et al. Smokeless tobacco use and health effects among baseball players. JAMA 1990;26:218-224.

24. Thomson WM, Broadbent JM, Welch D, Beck JD, Poulton R. Cigarette smoking and periodontal disease among 32-yearolds: a prospective study of a representative birth cohort. J Clin Periodontol. 2007 Oct;34(10):828-834.

25. Machtei EE, Christersson LA, Grossi SG, Dunford R, Zambon JJ, Genco RJ. Clinical criteria for the definition of "established periodontitis". J Periodontol 1992;63:206-214.

26. Haffajee AD, Socransky SS. Relationship of cigarette smoking to the subgingival microbiota. J Clin Periodontol 2001; 28:377-388.

27. Sachin S Shivanaikar, Mohamed Faizuddin, Kishore Bhat. Effect of smoking on neutrophil apoptosis in chronic periodontitis: An immunohistochemical study. Indian Journal of Dental Research 2013 Jan 1;24(1):147.

28. Martha E Nunn. Understanding the etiology of periodontitis: an overview of periodontal risk factors. Perio 20002003 Jun;32(1):11-23. 